\title{
ANÁLISE COMPARATIVA ENTRE AS MATRIZES CURRICULARES DOS CURSOS SUPERIORES DE TECNOLOGIA EM GESTÃO DA QUALIDADE (CSTGQ) PRESENCAIS EM CURITIBA - PR.
}

Heron Schonarth Aluno do Curso de Tecnologia em Gestão da Qualidade da Universidade Federal do Paraná. Artigo apresentado como. Trabalho de Conclusão de Curso. $7^{0}-2016$.

Paulo Eduardo Sobreira Moraes

Professor Orientador na Universidade Federal do Paraná.

\section{RESUMO:}

O presente artigo teve a finalidade de avaliar as matrizes curriculares de Cursos Superiores de Tecnologia em Gestão da Qualidade em Curitiba. Através de revisão bibliográfica foi possível identificar o perfil de graduação do Tecnólogo, uma vez que isto tem grande impacto no resultado da formação dos alunos. O trabalho também, a partir da análise das universidades e estruturas de ensino pode estabelecer uma base de comparativo entre o histórico e tendências das universidades, afim de desvendar cada uma das instituições. Realizando o enquadramento das matrizes em categorias foi possível estabelecer diferenças e similaridades entre as universidades que possuem o curso no seu portfólio. Tal analise foi estruturada em valores de igualdade e diferença entre as intuições na busca de possíveis padrões ou tendências.

Palavras-chave: Matrizes curriculares. Gestão da qualidade

\section{ABSTRACT:}

The present article had the purpose of evaluating the curricular matrices of the Superior Courses of Technology in Quality Management in Curitiba. Through a bibliographical review it was possible to identify the graduation profile of the Technologist, since it has a great impact on the result of the students training. The work also, from the analysis of universities and teaching structures, can establish a comparative basis between the history and trends of universities, in order to unveil each one of the institutions. By framing the matrices into categories it was possible to make comparisons and establish differences and similarities between the universities that have the course in their portfolio. This analysis was structured in values of equalityand difference between the intuitions in the search of possible patterns or tendencies.

Key-words: Curricular Matrices. Quality management

\section{INTRODUÇÃO}

O Curso Superior de Tecnologia está intrinsecamente ligado ao mercado de trabalho, uma vez que o foco é a preparação de profissionais com uma especialização maior na área 
de atuação e com uma capacitação mais rápida (2 à 3 anos). Tal especialização é entendida como o aprofundamento do estudo e compreensão da tecnologia para sua aplicação - no caso de Cursos Superiores de Tecnologia em Gestão da Qualidade o aprofundamento se dá na implantação, manutenção e no aperfeiçoamento dos misteres das organizações no tocante à Qualidade como função administrativa. "Atingir continuamente resultados consistentemente melhores em termos de Satisfação do Consumidor com nossos produtos e serviços. Processos e pessoas têm sido e sempre serão a chave para conseguirmos estes resultados." FORD (2015).

A estrutura de um curso é influenciada pelo mercado e por princípios regulamentadores - Sendo que muitas vezes estes princípios estão correlacionados no aspecto de criação e desenvolvimento dos cursos. No caso dos Cursos Superiores de Tecnologia temos dois principais regentes no âmbito regulamentador: o MEC e o Catálogo Nacional dos Cursos Superiores de Tecnologia, que tem o foco de avaliar e direcionar as estruturas dos cursos de acordo com a necessidade e potenciais do mercado. De acordo com MEC (2010) ao comparar o Brasil com outros países poderíamos justificar a possibilidade de avanço dos Tecnólogos, neste exemplo, temos no Brasil apenas 5\% das matriculas de graduação em tecnologias e nos EUA representam quase $50 \%$.

A tendência de criação de cursos superiores voltados para a absorção específica do mercado de trabalho impulsionou toda uma estrutura educacional, mas que não necessariamente impõe a aplicação da mesma grade curricular para todas as instituições de ensino. Portanto a variação entre os métodos de ensino poderia criar diferentes perfis de profissionais para o mercado. Para avaliar as similaridades e discrepâncias dos CSTGQ presenciais em Curitiba o presente artigo foi construído através da coleta de dados disponíveis nos sites oficiais de cada universidade entre os anos de 2015 e 2016. Segundo Moraes (2010), [...] a qualidade como atributo é função da comparação entre objetos: um tem qualidade porque é melhor que o outro sob algum sentido.

Para avaliar as grades curriculares o presente artigo se estruturou no desenvolvimento de categorias de afinidade para as matérias, onde foram estabelecidos seis itens com o intuito de agrupar as matérias: 1 - Ferramentas da Qualidade (FQ); 2Gestão e Estratégias (GE); 3- Economia, Contabilidade e Custos (ECC); 4- Marketing, Relações Humanas e Sociais (MHS); 5-Processo e Produção (PP); 6- Estatística e Métodos Quantitativos(EM). Segundo Moraes (2010), em uma das percepções conceituais 
de qualidade de conformidade a qualidade é a condição de execução de um serviço ou a produção de um bem na maior consonância e concordância possível a seu projeto.

Cabe destacar que o artigo não foi construído para apontar o melhor curso ou 0 melhor formato de enquadramento em categorias, mas sim, para verificar a representatividade de cada categoria em cada universidade dentro de dados numéricos, visualizar as suas tendências e também contribuir com o entendimento do perfil do Tecnólogo em Gestão da Qualidade através da exposição de alguns fatores do tema.

\section{ESTRUTURA DE ENSINO}

Em análise a orientação de estruturação das entidades de ensino que pretendem ofertar Cursos Superiores de Tecnologia em Gestão da Qualidade é avaliado primeiramente se o curso atende as necessidades do mercado e o perfil de formação que 0 profissional precisaria para atender o mercado - tal avaliação e estudo é realizado pelo MEC através de pesquisa de mercado.

"O tecnólogo em Gestão da Qualidade desenvolve avaliação sistemática dos procedimentos, práticas e rotinas internas e externas de uma organização, dominando e aplicando as normas e padrões referentes aos sistemas certificáveis. O profissional pode atuar como auditor interno ou em entidades de certificação. Proceder à análise da situação da organização, seus métodos de trabalho e produtos; elaborar e gerenciar estratégias de implantação para obtenção de determinada certificação, a exemplo de qualidade, meio ambiente, saúde ocupacional e responsabilidade corporativa socioambiental; supervisionar as alterações no processo produtivo; além de capacitar os profissionais envolvidos, são algumas das possibilidades de atuação deste profissional." MEC (2010).

A partir das delimitações e pretensões da graduação é possível observar o foco das estruturas de ensino e qual perfil de egresso o mercado poderia receber. Contudo é importante ponderar a forma de graduação e os seus impactos. MACHADO (2008) avaliou importantes aspectos históricos da legislação educacional brasileira e do contexto de expansão dos cursos superiores de tecnologia no país para avaliar a identidade, dificuldades e potenciais do tecnólogo. Este tema levantado é muito importante para os Cursos de Tecnologia, uma vez que representam algo diferente a nível de graduação para sociedade brasileira - o ser humano tem naturalmente receio daquilo que não tem muita informação. Saber que a Graduação no formato de tecnologia apresenta variações de aceitação na sociedade, avaliar que estes cursos tem variações de aceitação quando 
ofertados por entidade públicas ou privadas, mas que quando possuem uma estrutura governamental de apoio a oferta assumem maior representatividade em ambos formatos. Avaliar o que os estilos de graduação apresentam de diferenças e onde isso poderia ser uma vantagem ou desvantagem, tanto para o graduado, tanto para o mercado poderiam ajudar a sanar a falta de informação sobre os cursos.

Ao entender a orientação do mercado e a metodologia de ensino é possível encontrar informações intrínsecas ao título de tecnólogo em gestão da qualidade. Segundo MACHADO (2008) a graduação de tecnólogo remete ao titular o perfil de profissional que tem a habilidade de estudar a tecnologia humana. Portanto no caso de um tecnólogo de gestão da qualidade, o foco seria ter conhecimento sobre diversas ferramentas de gestão e da qualidade, além de conhecer diferentes estruturas e/ou departamentos que as empresas costumam utilizar, conferindo portanto ao conhecedor a capacidade de avaliar de maneira assertiva a tecnologia correta para as situações ou problemáticas encontradas. Por isso vale ressaltar que a grade curricular precisa ter o papel de estruturar o conhecimento que 0 tecnólogo irá adquirir.

\subsection{AS INSTITUIÇÕES AVALIADAS}

Dentro dos requisitos para seleção das universidades que seriam avaliadas - ano de 2016, Tecnologia de gestão da qualidade na modalidade presencial e em Curitiba. Foram encontradas cinco universidades, CETEP, UFPR, PUC, SANTA CRUZ, SOCIESC. Segundo Moraes, Franco e Silva (2010) o conceito da qualidade é insustentável e leve apresentando vários conceitos fundamentais oriundos da diferença ou da igualdade gerado pela expectativa de qualidade. Adotar uma metodologia para avaliar matrizes curriculares dos cursos de TGQ em instituições diferentes significa aceitar que na busca do enquadramento seria possível encontrar na diferença e na igualdade razões para conferir avaliações aos cursos.

\section{TABELA 1}

Apresenta as características de agrupamento das matérias das instituições dentro das categorias elegidas para análise em horas.

\begin{tabular}{|c|c|c|c|c|c|}
\hline Categoria & $\begin{array}{l}\mathrm{d} \\
\text { ETEP FPR }\end{array}$ & & a Cruz & $\begin{array}{r}\text { SO } \\
\text { CIESC }\end{array}$ & édia \\
\hline 1 Ferramentas da Qualidade & $5 \quad 51$ & & $5 \quad 500 h$ & 480 & \\
\hline
\end{tabular}




\begin{tabular}{|c|c|c|c|c|}
\hline & \begin{tabular}{l|l}
$60 \mathrm{~h}$ & $0 \mathrm{~h}$
\end{tabular} & $60 \mathrm{~h}$ & r & $22 \mathrm{~h}$ \\
\hline 2 Gestão e Estratégias & $40 h^{4}$ oh & $30 a_{00 h} 6$ & $320 \mathrm{~h}$ & $280{ }_{88 h^{3}}$ \\
\hline $\begin{array}{l}3 \text { Economia, Contabilidade e } \\
\text { Custos }\end{array}$ & $\mathrm{en}_{\mathrm{Oh}} \mathrm{O}_{\mathrm{Oh}}$ & 12 on 8 & $120 \mathrm{~h}$ & $80 \mathrm{~h} 6 \mathrm{6h}$ \\
\hline $\begin{array}{l}4 \quad \text { Marketing, Relações } \\
\text { Humanas e Sociais }\end{array}$ & $80 h^{2} 0 h$ & $304_{40 h^{2}}^{2}$ & $240 \mathrm{~h}$ & $24060 \mathrm{~h}$ \\
\hline 5 Processo e Produção & $60 \mathrm{~h}^{1} \mathrm{~h}$ & $\left.90\right|_{60 h} 1$ & $80 \mathrm{~h}$ & $16030 \mathrm{~h}$ \\
\hline $\begin{array}{l}6 \text { Estatística e Métodos } \\
\text { Quantitativos }\end{array}$ & on 8 on & $15{ }_{60 h}^{1}$ & $200 \mathrm{~h}$ & \begin{tabular}{l|l}
400 & $98 \mathrm{~h}$ \\
\end{tabular} \\
\hline Total em horas & $600^{1 / 70}$ & $\left.14\right|_{800} ^{1}$ & 1460 & $\left.164\right|_{594^{1}} ^{1}$ \\
\hline
\end{tabular}

Fonte: $O$ autor.

A tabela 1, representa o resumo das grades curriculares das entidades avaliadas, com ela já foi possível notar a variação existente entre os cursos. Ressalto aqui a diferença no total de horas avaliadas entre os cursos. Encontrando a PUC com 1.800 horas, representando cerca de $23 \%$ a mais que a UFPR e SANTA CRUZ. Por outro lado, o CETEP e o SOCIESC ficaram muito próximos de uma suposta média entre a menor e maior carga horaria.

\section{TABELA 1.1}

Apresenta as características de agrupamento das matérias das instituições dentro das categorias elegidas para análise em unidade.

\begin{tabular}{|c|r|r|r|r|r|r|r|}
\hline Categoria & \multicolumn{2}{|c|}{$\begin{array}{l}\text { C } \\
\text { ETEP FPR }\end{array}$} & UC & A CRUZ & CIESC & édia \\
\hline 1 Ferramentas da Qualidade & 7 & 1 & 7 & 8 & 6 & 7 \\
\hline 2 Gestão e Estratégias & 6 & 8 & 8 & 6 & 4 & 6 \\
\hline $\begin{array}{c}3 \text { Economia, Contabilidade } \\
\text { Custos }\end{array}$ & 1 & 3 & 1 & 2 & 1 & 1 \\
$\begin{array}{l}4 \quad \text { Marketing, Relações } \\
\text { Humanas e Sociais }\end{array}$ & 4 & 6 & 4 & 5 & 4 & & 4 \\
\hline
\end{tabular}




\begin{tabular}{|l|l|l|l|l|l|l|ll|}
\hline 5 Processo e Produção & 2 & 2 & 2 & 1 & 2 & & 1 \\
\hline $\begin{array}{c}6 \quad \text { Estatística e Métodos } \\
\text { Quantitativos }\end{array}$ & 1 & 3 & 2 & 3 & 5 & 2 \\
\hline Total & 1 & 2 & 3 & 2 & 25 & 22 & 2 \\
\hline
\end{tabular}

Fonte: $\mathrm{O}$ autor.

A tabela 1.1 destaca a distribuição na forma unitária de cada uma das matérias nas categorias avaliadas dentro de cada uma das entidades. A dispersão pela quantidade de matérias, indica a quantidade conteúdos proposta por cada universidade - tomando como base que cada matéria possui uma ementa e conteúdos propostos. Destaca-se aqui a UFPR com 32 matérias que representa $52,38 \%$ a mais que a quantidade proposta pelo CETEP. Em contrapartida ao realizar uma média entre todas as entidades, a PUC e SANTA CRUZ têm destaque, pois estão mais próximos a média de 24,8 .

\section{TABELA 1.2}

Representa a combinação entre a as tabelas 1 e 1.1 para comparativo das categorias elegidas em horas/matérias.

\begin{tabular}{|c|c|c|c|c|c|c|}
\hline Categoria & ${ }_{\text {ETEP }}^{\mathrm{O}}$ FPR U UC & $\mathrm{P}_{\mathrm{a}}$ & $\begin{array}{l}\text { Sant } \\
\text { uz }\end{array}$ & $\begin{array}{r}\text { SO } \\
\text { CIESC }\end{array}$ & édia & $\mathrm{M}$ \\
\hline 1 Ferramentas da Qualidade & $0 \begin{array}{llll}0 & 8 & 5 & \end{array}$ & 8 & 62,5 & 80 & 70 & 70 \\
\hline 2 Gestão e Estratégias & $3,33^{7} 7,50^{3} 5$ & 7 & 53,3 & 70 & ,83 & 61 \\
\hline $\begin{array}{l}3 \text { Economia, Contabilidade } \epsilon \\
\text { Custos }\end{array}$ & \begin{tabular}{ll|ll}
0 & 8 & & 4 \\
0 & 0 & 0
\end{tabular} & 8 & 60 & 80 & & 68 \\
\hline $\begin{array}{cc}4 & \text { Marketing, } \\
\text { Humanas e Sociais } & \text { Relações }\end{array}$ & $7{ }_{0}$ & 6 & 48 & 60 & 60 & 57 \\
\hline 5 Processo e Produção & $\left.4\right|_{0}$ & 8 & 80 & 80 & & 73 \\
\hline $\begin{array}{ccc}6 & \text { Estatística } & \text { e } \\
\text { Quantitativos }\end{array}$ & \begin{tabular}{|ll|ll} 
& 8 & & 5 \\
0 & & & 0
\end{tabular} & 8 & 66,6 & 80 & 33 & 71 \\
\hline Total & $6,19^{7} 5,94^{4}$ & 7 & 58,4 & 55 & 01 & 66 \\
\hline
\end{tabular}

Fonte: O autor.

A tabela 1.2 demostra a média das horas aulas para cada uma das categorias para cada uma das entidades. Com ela é possível visualizar a dispersão de cada uma das faculdades. Aqui destaca-se a diferença de abordagem para cada um dos temas assumindo a média de tempo por categoria fica possível ponderam quanto tempo cada universidade dedica por tema. A tabela revela que a UFPR possui a menor média $(45,93 \%)$ 
utiliza uma metodologia com amplitude de 37,50 e 51\% horas aula médias entre categorias e em contrapartida o CETEP possuí a maior média (76,19\%) com amplitude de 70 a 80 horas aula médias entre categorias. A abordagem da PUC e da SOCIESC estão próximas ao praticado pelo CETEP, respectivamente $75 \%$ e $74,54 \%$ e amplitude iguais 60 a 80 horas aula médias entre categorias. Já a Santa Cruz com a média de 58,40\% e amplitude de 48 a 80 horas aula médias entre categorias.

\section{FACULDADE CETEP DE TECNOLOGIA}

A entidade CETEP Ensino foi fundada em 1986 e possui opções de ensino a distância, profissionalizantes, técnicos, graduação tecnológica, pós-graduação. Ao destacar a missão foi possível evidenciar o propósito do CETEP na capacitação de pessoas para o ingresso e/ou acessão no mercado de trabalho. (CETEP, 2016).

$\mathrm{Na}$ instituição eram ofertados três cursos no âmbito de graduação tecnológica: Tecnologia em Gestão da Qualidade, Tecnologia em Automação Industrial, Tecnologia em Eletrônica Industrial.

Ao avaliar o Curso Superior em Tecnologia da Qualidade foi possível observar a ligação a missão da entidade em formar capital humano para o mercado. Mas ao destacar - objetivo do curso foi possível ponderar que a preocupação está relacionada em apresentar à excelência em produtos e serviços nas atividades empresarias através da qualidade.

\section{GRÁFICO 1}

Apresenta a distribuição e frequência de cada categoria tabelada com base na matriz curricular do CETEP

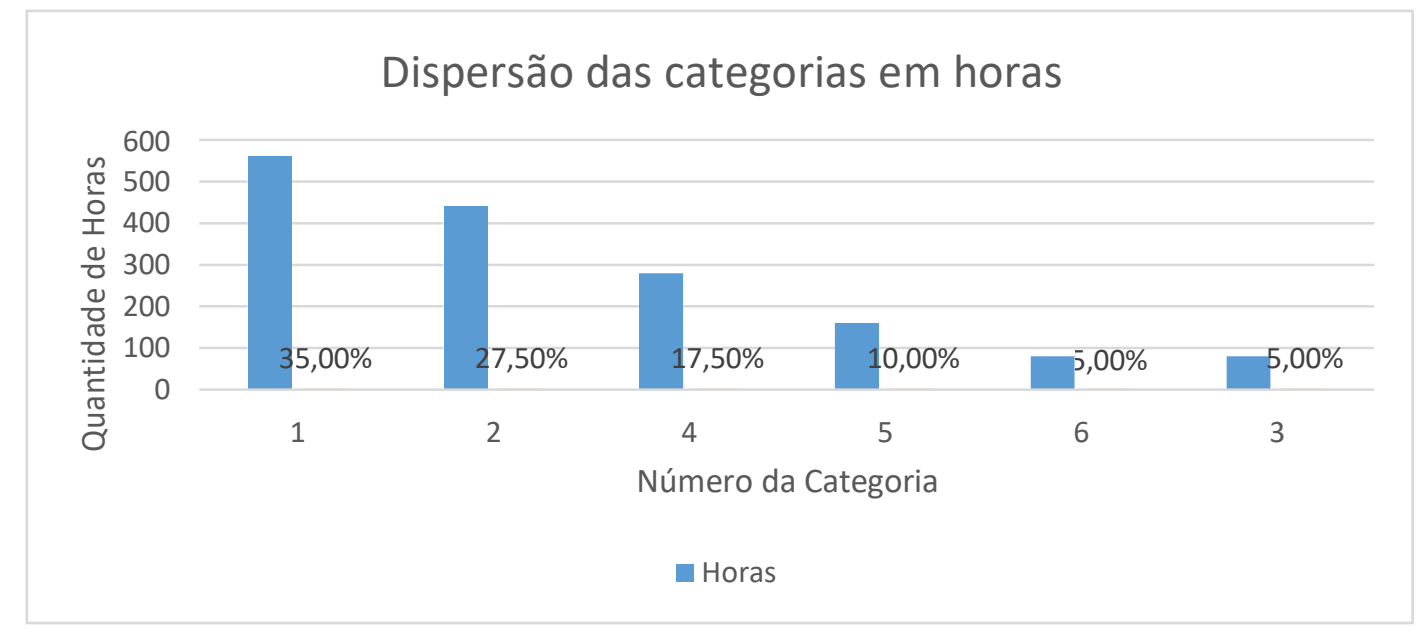


Fonte: $\mathrm{O}$ autor.

Para analisar o gráfico foi necessário definir um padrão, deste modo faço uma consideração - que também será levada em conta nas demais análises. Ao aceitar a categorização de matérias em classes é assumida uma classificação para avaliação do grupo que restringe informações detalhadas. Mas em contrapartida também fica possível, de uma forma mais organizada, ponderar discrepâncias e igualdades. Ao realizar um gráfico com seis categorias e considerando que o objeto avaliado representa $100 \%$ em sua totalidade, o resultado oriundo desta divisão em partes igualitárias seria 16,66\% para cada categoria - partindo desta referência pretendo posicionar a concentração de cada uma das categorias nas matrizes curriculares.

Destacou-se na distribuição da grade horaria do CETEP a valorização das categorias 1, 2 e 4 (Ferramentas da Qualidade; Gestão e Estratégias; Marketing, Relações Humanas e Sociais) onde, na mesma ordem, apresentaram valorização de 110,08\%, 65,06\% e $5,04 \%$ em relação à média de horas aula. As demais categorias 5, 6 e 3 (Economia, Contabilidade e Custos; Processo e Produção; Estatística e Métodos Quantitativos) apresentaram, respectivamente, desvalorização de 39,98\%, 69,99\% e 69,99\%.

\section{GRÁFICO 1.1}

Apresenta a evolução acumulada de cada categoria tabelada com base na matriz curricular do CETEP

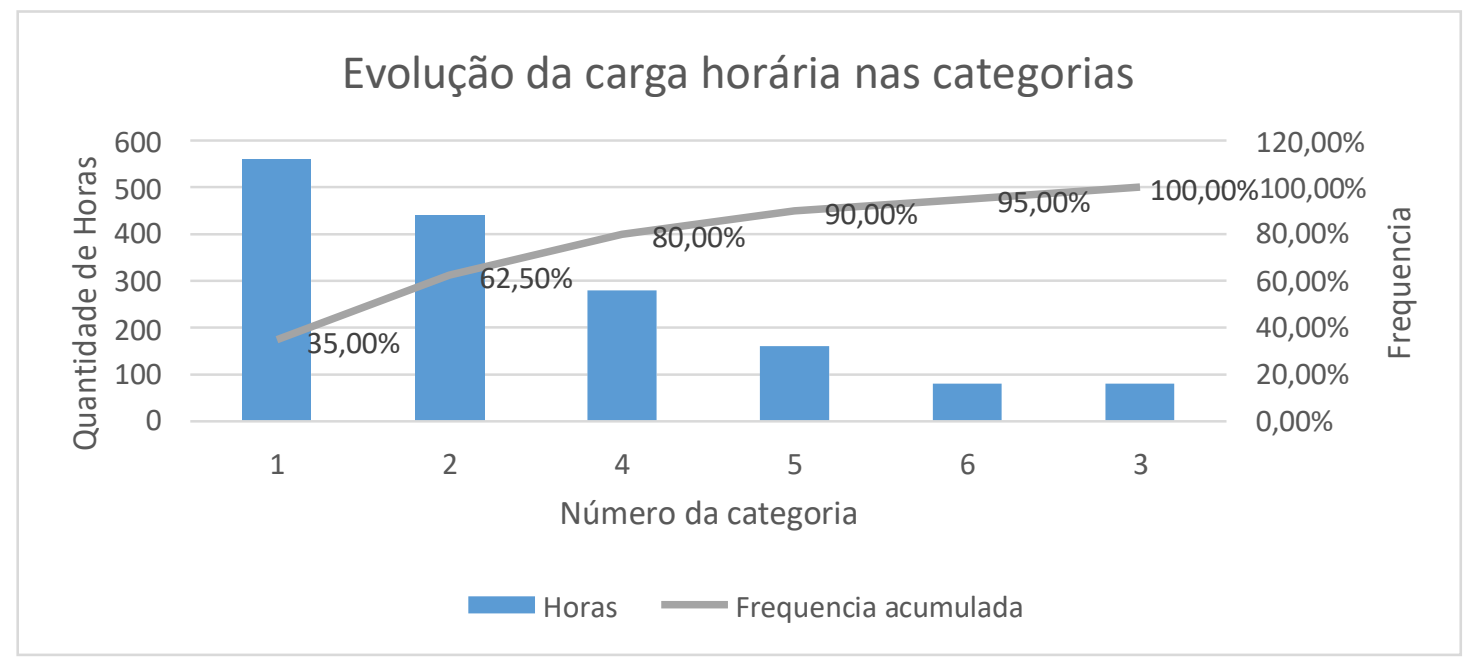

Fonte: O autor.

Destacou-se a concentração de $80 \%$ do tempo do curso nas categorias 1, 2 e 4 (Ferramentas da Qualidade; Gestão e Estratégias; Marketing, Relações Humanas e 
Sociais) o que indica o direcionamento do curso em seguir as principais técnicas de especialização para o aluno atender a demanda do mercado em qualidade e gestão com a preocupação a áreas humanas. Já os $20 \%$ restantes do curso indicam a tendência da universidade em apresentar os conhecimentos complementares através das categorias 3, 5 e 6 (Economia, Contabilidade e Custos; Processo e Produção; e Estatística e Métodos Quantitativos).

\section{Pontifícia Universidade Católica do Paraná (PUC-PR)}

A Universidade PUC é parte integrante do grupo marista que tem diversos meios de atuação onde se destaca a missão de "Formar cidadãos éticos, justos e solidários para a transformação da sociedade, por meio de processos educacionais fundamentados nos valores do Evangelho, do jeito Marista." (Marista, 2016). Em consequência deste ideal a PUC tem uma clara posição a seguir estes preceitos mas destaca que a sua vocação em justificar que antes de tudo é uma Universidade.

A Universidade oferta cursos de Graduação, Mestrado e Doutorado, Técnico, Tecnólogo, Especialização, Cursos de línguas. Na área de cursos Tecnólogos são ofertados oito cursos (Gestão Comercial, Gestão da Qualidade, Gestão de Recursos Humanos, Logística, Gastronomia, Gestão da Produção Industrial, Sistemas para Internet, Jogos Digitais). Estes cursos foram resultado de pesquisas da própria instituição que destaca uma interessante pesquisa de mercado:

"As empresas, aos poucos, conhecem esse novo perfil de profissional e verificam que o tecnólogo possui uma formação bastante sólida. De acordo com as pesquisas da PUCPR realizadas com 55 grandes empresas de Curitiba, 43\% das admissões realizadas na cidade, em 2008, poderiam ser atendidas por tecnólogos." (PUC, 2016).

A partir da justificativa do potencial desta modalidade de cursos, é possível observar a pretensão da Universidade em explorar esta oportunidade de mercado e o motivo de apostar em 8 cursos desta modalidade. Especificamente o Curso de Gestão da Qualidade da PUC foi descrito o nicho de mercado e a previsão de colocação do profissional onde em um mercado instável e globalizado poderá ter um incremento da competitividade organizacional através da qualidade onde ainda segundo:

"Para atender a estes desafios o profissional da Qualidade precisa apresentar 
competências técnicas associadas às práticas de gestão de pessoas e competências conceituais que possibilitem o entendimento de seu papel na organização em que atua." (PUC, 2016).

\section{GRÁFICO 2}

Apresenta a evolução e frequência de cada categoria tabelada com base na matriz curricular do PUC.

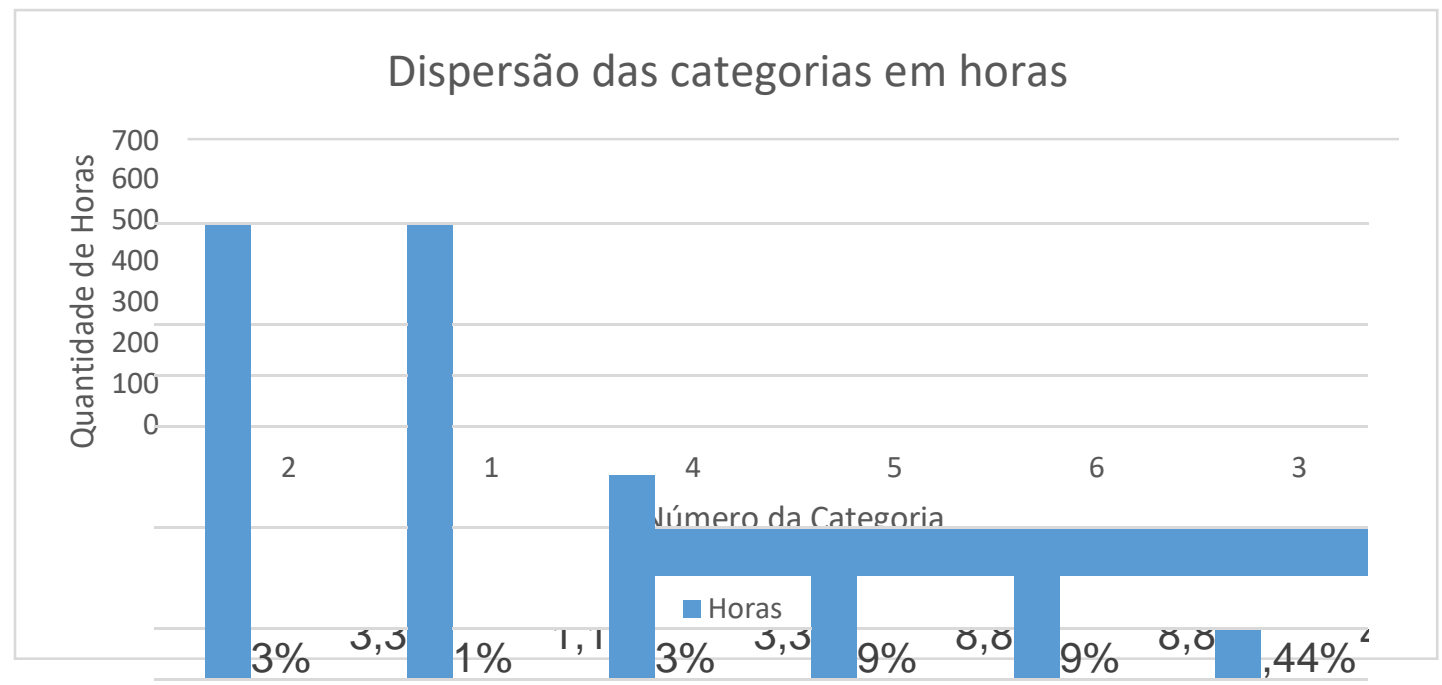

Fonte: $\mathrm{O}$ autor.

Na distribuição da grade horaria da PUC foi observado nas categorias 2 e 1 (Gestão e Estratégias; Ferramentas da Qualidade) onde, na mesma ordem, apresentaram valorização de 100,06\%, 92,51\% em relação à média de horas aula. As demais categorias 4, 5, 6 e 3 (Marketing Relações Humanas e Sociais; Processo e Produção; Estatística e Métodos Quantitativos; Economia, Contabilidade e Custos) apresentaram, respectivamente, desvalorização de 19,99\%, 46,63\%, 46,63\%,

$73,34 \%$.

\section{GRÁFICO 2.1}

Apresenta a evolução acumulada de cada categoria tabelada com base na matriz curricular do PUC.

\section{Evolução da carga horaria nas categorias}

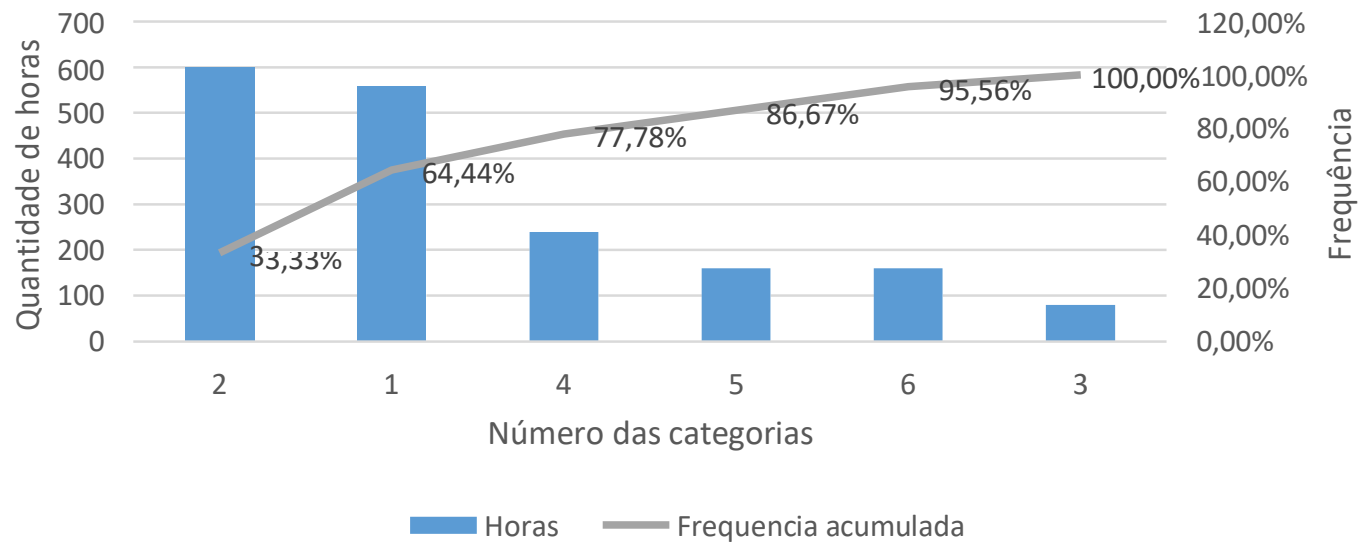


Fonte: O autor.

No Gráfico 2.1 destacou-se a concentração de $77,78 \%$ do tempo do curso nas categorias 2, 1 e 4 (Gestão e Estratégias; Ferramentas da Qualidade; Marketing, Relações Humanas e Sociais) o que indica o direcionamento do curso em seguir as principais técnicas de especialização para o aluno atender a demanda do mercado em qualidade e gestão com a preocupação a áreas humanas. Já os $22,22 \%$ restantes do curso indicam a tendência da universidade em apresentar os conhecimentos complementares através das categorias 5, 6 e 3 (Processo e Produção; Estatística e Métodos Quantitativos; Economia, Contabilidade e Custos).

\section{Faculdades Santa Cruz}

A entidade Santa Cruz foi fundada em 1993 da origem da integração das Faculdades Reunidas Santa Cruz de Curitiba e a Faculdade de Ciências Sociais de Araucária, mantida pela União Paranaense de Ensino e Cultura - Unipec. Segundo Santa Cruz (2016) foram avaliados a localização para uma parte mais estratégica da cidade, no mesmo ano foram ofertados os primeiros cursos da entidade.

Para entender o perfil de Ensino a descrição da missão serviu como "Desenvolver competências e valores com seriedade, formando cidadãos e profissionais para o mundo" Santa Cruz (2016). A partir do perfil de ação que entidade adotou é possível ponderar que a preocupação excede as linhas do conhecimento para uma formação humanizada, visando o cidadão.

A entidade oferta em seu portfólio cursos de Extensão, Capacitação, Bacharelado, Tecnologia, Licenciatura e Pós-graduação. Sendo seis deles tecnológicos (Tecnologia em Logística, Tecnologia em Gestão da qualidade, Tecnologia em Gestão de Recursos Humanos, Tecnologia em Marketing, Tecnologia em redes de computadores, Tecnologia em Gestão da Tecnologia da Informação). Para os interessados na graduação de Tecnologia em Gestão da qualidade foi interessante observar a visão da entidade sobre o potencial onde é delimitado em SANTA CRUZ (2016) que em um mercado competitivo e instável um Gestor da Qualidade irá auxiliar no desenvolvimento das competências técnicas e humanas. Para ressaltar o objetivo é apresentado ainda que o pretendido é 
formar profissionais capacitados sendo auditores internos ou externos para avaliar e desenvolver práticas e rotinas internas e externas de uma organização.

\section{GRÁFICO 3}

Apresenta a distribuição e frequência de cada categoria tabelada com base na matriz curricular do SANTA CRUZ.

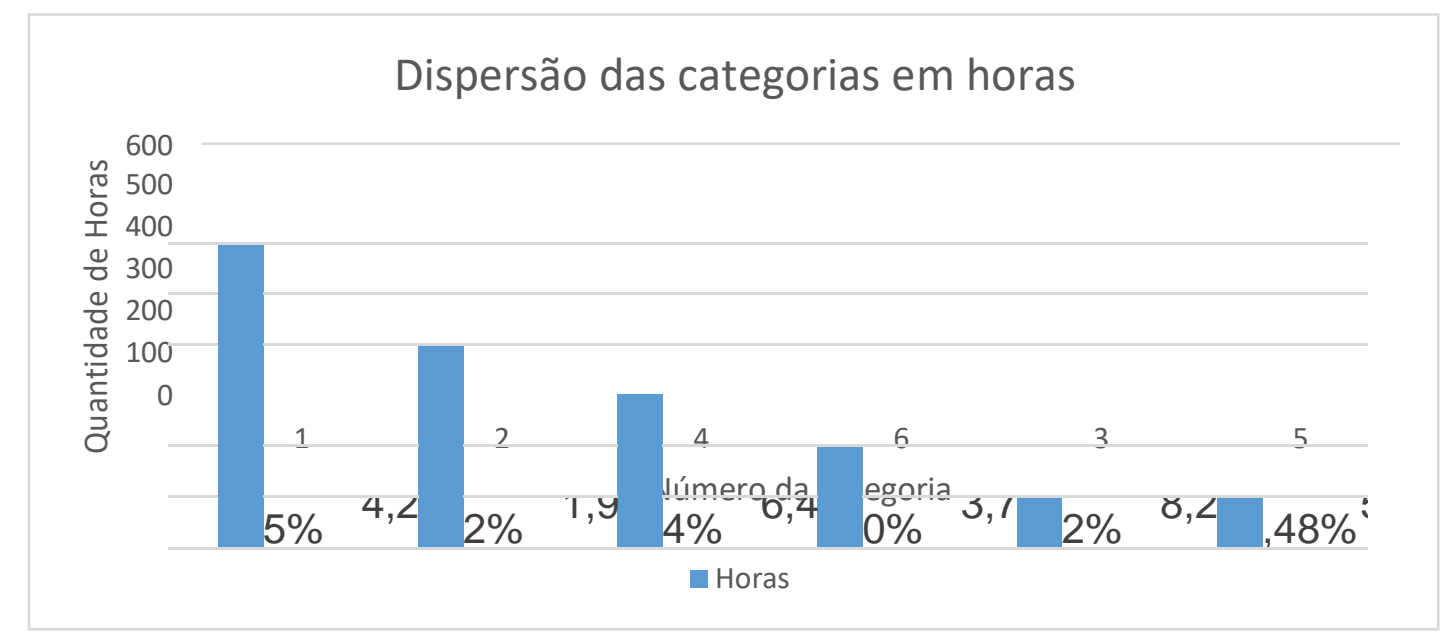

Fonte: $\mathrm{O}$ autor.

$\mathrm{Na}$ grade horaria da Santa Cruz foi observado as categorias 1 e 2 (Ferramentas da Qualidade; Gestão e Estratégias;) onde, na mesma ordem, apresentaram valorização de 105,58\%, 31,57\% em relação à média de horas aula. A Categoria 4 (Marketing, Relações Humanas e Sociais) uma leve desvalorização de 1,32\%. As demais categorias 5,6 e 3 (Processo e Produção; Estatística e Métodos Quantitativos; Economia, Contabilidade e Custos) apresentaram, respectivamente, desvalorização de 17,76\%, 50,66\%, 67,10\%. GRÁFICO 3.1

Apresenta a evolução acumulada de cada categoria tabelada com base na matriz curricular do SANTA CRUZ. 


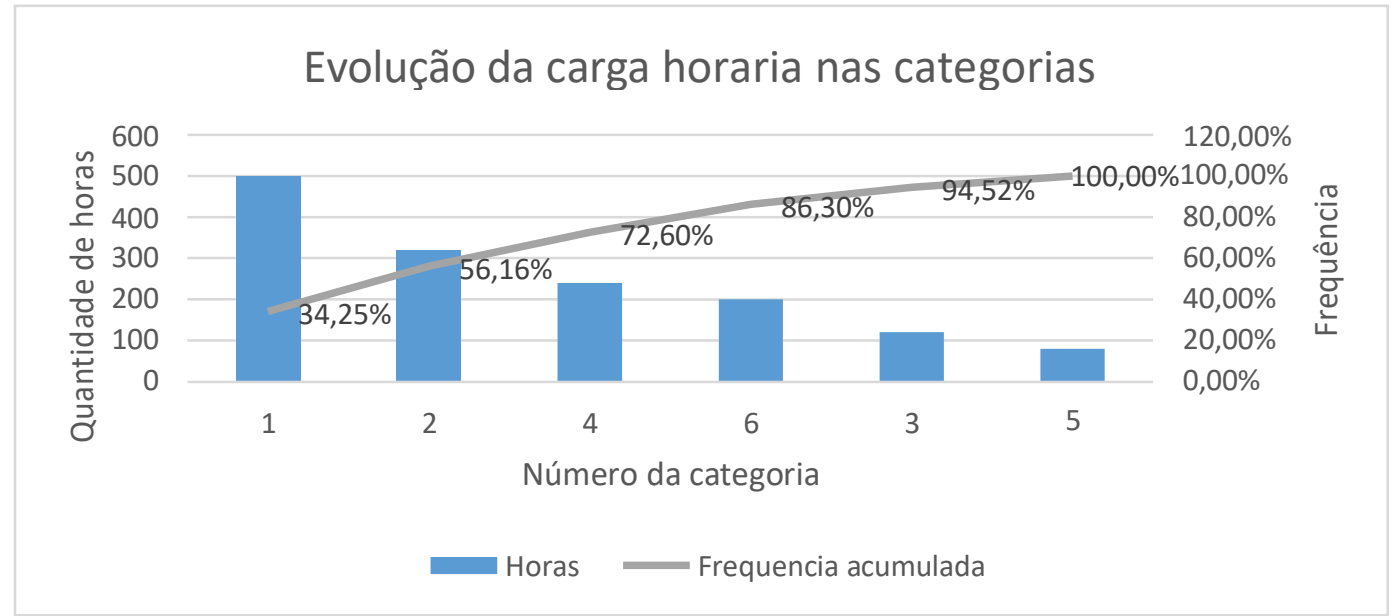

Fonte: $\mathrm{O}$ autor.

Ressalta-se a concentração de $72,60 \%$ do tempo do curso nas categorias 1,2 e 4 (Ferramentas da Qualidade; Gestão e Estratégias; Marketing, Relações Humanas e Sociais) o que indica o direcionamento do curso em seguir as principais técnicas de especialização para o aluno atender a demanda do mercado em qualidade e gestão com a preocupação a áreas humanas. Já os $27,40 \%$ restantes do curso indicam a tendência da universidade em apresentar os conhecimentos complementares através das categorias 6, 3 e 5 (Estatística e Métodos Quantitativos; Economia, Contabilidade e Custos; Processo e Produção).

\section{UNIVERSIDADE FEDERAL DO PARANÁ (UFPR)}

A UFPR é a Universidade mais antiga do Brasil. Interessante destacar aqui que o movimento de criação da Universidade foi fruto da necessidade de mais profissionais qualificados. O que ainda costuma ser uma realidade para criação de novos cursos. "Foi apenas em 1912, quando avaliou-se que o Paraná precisava de mais profissionais qualificados, iniciou um movimento pró-Universidade do Paraná”. UFPR (2015).

Após avaliar o histórico de criação da entidade foi possível observar a responsabilidade de proporcionar ao mercado de trabalho profissionais competentes e atualizados de acordo com o momento econômico-social. Observando fatores como este no primeiro semestre de 2009 teve início o TGQ, fatores que foram reposicionados, e destaca-se, segundo avaliação para reformulação do curso a elevação do nível global de competitividade da produção implica no fortalecimento de diversos segmentos, tornando 
central o papel das atividades relacionadas à gestão da qualidade TGQ (2015).

A entidade oferta em seu portfólio cursos de Extensão, educação técnica, Bacharelado, Tecnologia, Licenciatura, Especialização, Mestrado e Doutorado. Sendo oito deles tecnológicos (Tecnologia em Análise e Desenvolvimento de Sistemas, Tecnologia em Produção Cênica, Tecnologia em Comunicação Institucional, Tecnologia em Gestão da Qualidade, Tecnologia em Gestão Pública, Tecnologia em Luteria, Tecnologia em Secretariado, Tecnologia em Negócios Imobiliários).

O curso ainda em seu material destaca qual é o perfil pretendido para os egressos:

"O egresso do Curso Superior de Tecnologia em Gestão da Qualidade deverá ser, antes de tudo, um profissional com reconhecida competência em gestão e processos da qualidade. Apresentar-se à sociedade como um profissional integrado à realidade do local onde está inserido, respeitando e aplicando posturas e condutas éticas em suas ações. "

GRÁFICO 4

Apresenta a distribuição e frequência de cada categoria tabelada com base na matriz curricular do UFPR

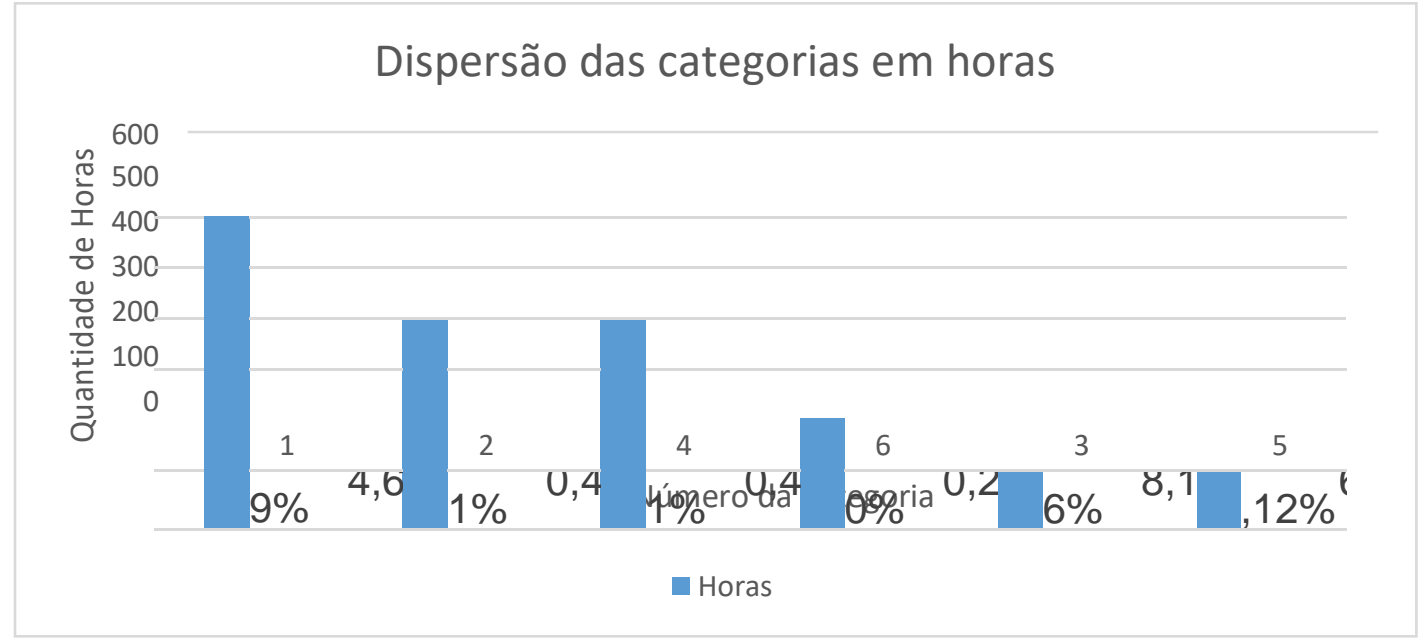

Fonte: O autor.

$\mathrm{Na}$ representação da grade da UFPR foi observado a categorias 1 (Ferramentas da Qualidade) com valorização de 108,22\%. Já as categorias 2 e 4 (Gestão e Estratégias; Marketing, Relações Humanas e Sociais) apresentaram a mesma valorização, 32,48\% em relação à média de horas aula. As demais categorias 6, 3 e 5 (Estatística e Métodos Quantitativos; Economia, Contabilidade e Custos; Processo e Produção) apresentaram, respectivamente, desvalorização de 38,77\%, 51,02\%, 63,26\%.

GRÁFICO 4.1 
Apresenta a evolução acumulada de cada categoria tabelada com base na matriz curricular do UFPR

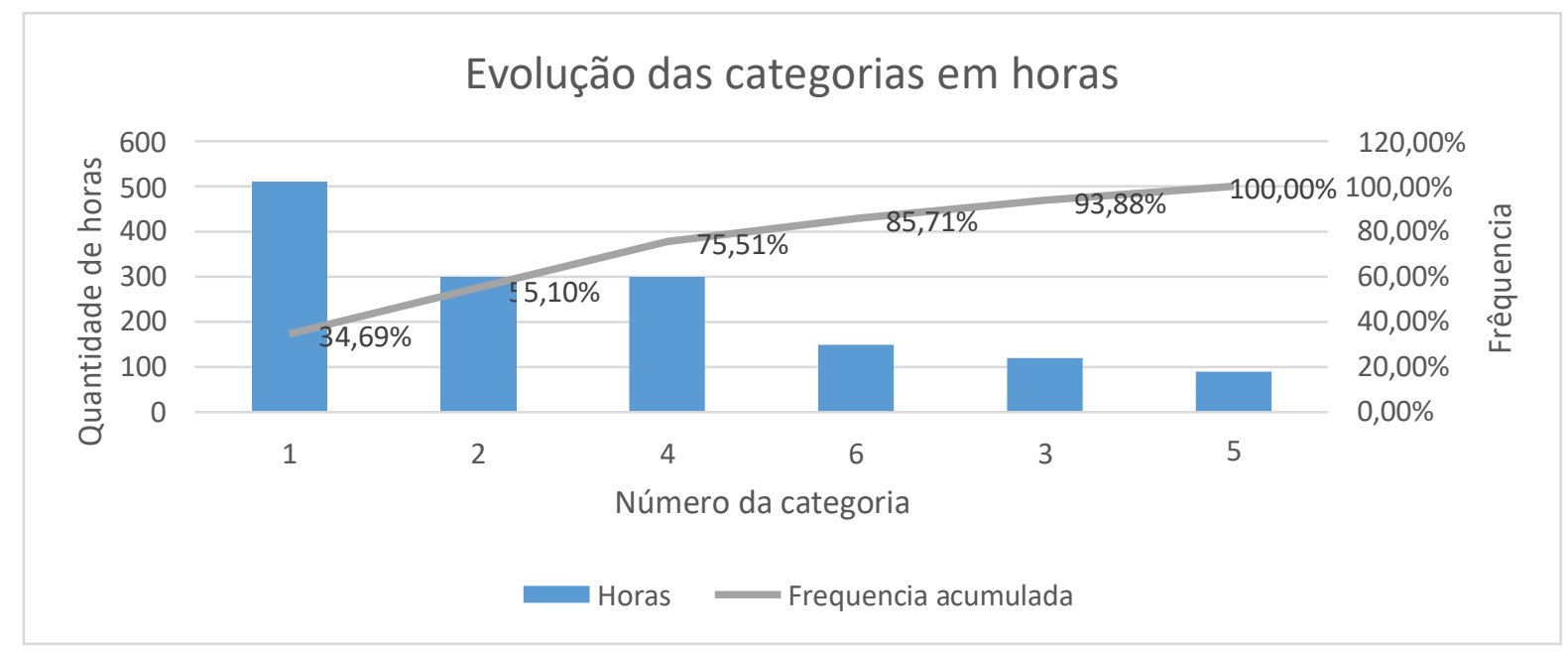

Fonte: $\mathrm{O}$ autor.

No caso da UFPR a concentração de 75,51\% do tempo do curso nas categorias 1, 2 e 4 (Ferramentas da Qualidade; Gestão e Estratégias; Marketing, Relações Humanas e Sociais) o que indica o direcionamento do curso em seguir as principais técnicas de especialização do aluno nestas classes. Já os $24,49 \%$ restantes do curso indicam a tendência da universidade em apresentar os conhecimentos complementares através das categorias 6, 3 e 5 (Estatística e Métodos Quantitativos; Economia, Contabilidade e Custos; Processo e Produção).

\section{Sociedade Educacional de Santa Catarina - SOCIESC}

A história do grupo começou em 1959, mas foi em 1985 que iniciou o nome SOCIESC e um processo de gestão independente. A partir deste processo ocorrem algumas transformações até meados dos anos 2000 onde foi feito um novo planejamento estratégico. "A necessidade de um modelo independente e forte para a Sociesc, foi criteriosamente desenhado em seu planejamento estratégico a partir de 2000 , sob direção de Sandro Murilo Santos." Sociesc (2016)

Ressalta-se que devido a orientação da entidade a desenvolver parcerias com empresas, possibilitou uma especialização na leitura da necessidade do mercado. "Neste novo contexto, as empresas passaram a serem parceiras na formação de profissionais técnicos, graduados e pós-graduados, e em projetos de pesquisa e extensão, 
desenvolvimento e consultoria tecnológica." Sociesc (2016).

O grupo possui Ensino Fundamental, Médio, Ensino Técnico, Ensino a distância, Graduação, Pós-Graduação. Sendo sete deles tecnológicos (Tecnólogo em Logística, Tecnólogo em Mecânica, Tecnologia em Gestão de Qualidade, tecnólogo em Eletrônica Industrial, tecnólogo em Mecatrônica Industrial, Tecnólogo em Polímeros, tecnologia em Processos Químicos). Na oferta do curso de gestão da qualidade a entidade delimitou sobre o perfil do futuro profissional:

"O Curso Superior de Tecnologia em Gestão de Qualidade tem como objetivo principal preparar profissionais capazes de conduzir a implantação de sistemas de gestão de qualidade, analisar criticamente os processos produtivos, propor melhorias de processos e produtos através de evidencias qualitativas e quantitativas, coordenar equipes e prestar consultoria no âmbito da qualidade." Sociesc (2016)

\section{GRÁFICO 5}

Apresenta a distribuição e frequência de cada categoria tabelada com base na matriz curricular da SOCIESC

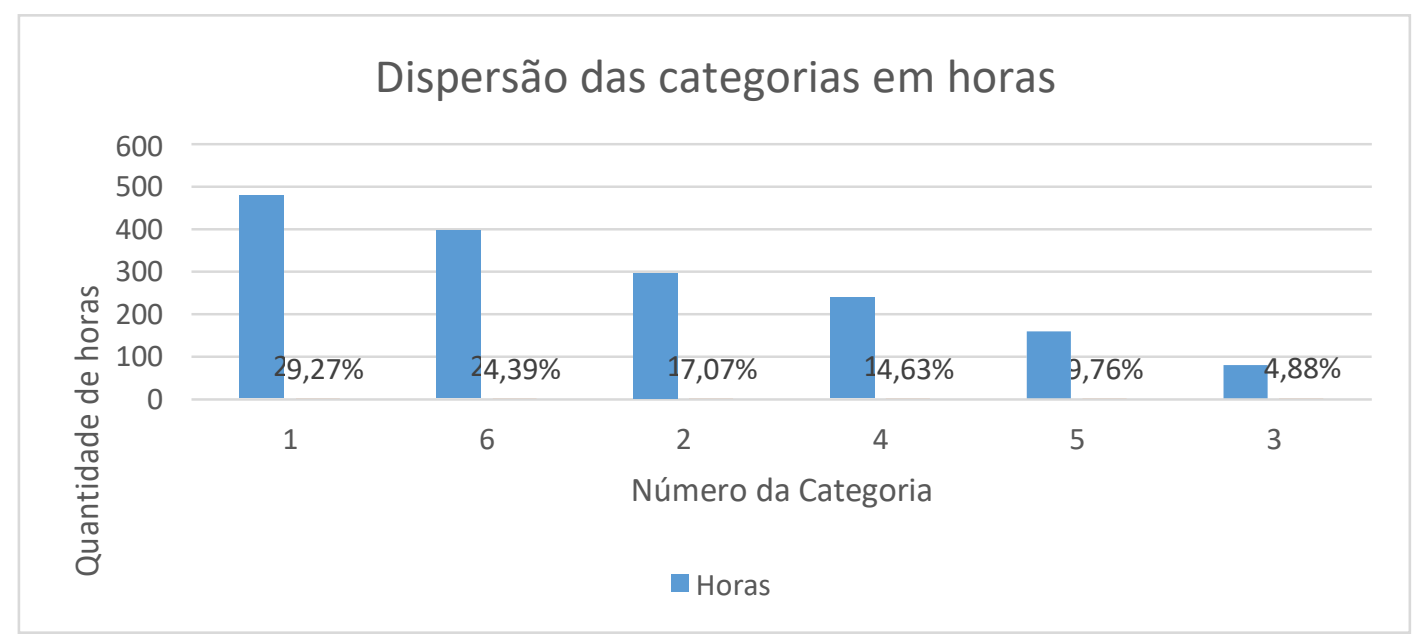


Fonte: O autor.

$\mathrm{Na}$ representação da grade da SOCIESC foi observado as categorias 1 e 6 (Ferramentas da Qualidade; Estatística e Métodos Quantitativos) onde apresentaram valorização de 75,69\%, 46,39\% em relação à média de horas aula. Já a categoria 2 (Gestão e Estratégias) a presentou uma pequena valorização de 2,46\%. As demais categorias 4, 5 e 3 (Marketing, e Relações Humanas e Sociais; Processo e Produção; Economia, Contabilidade e Custos) apresentaram, respectivamente, desvalorização de $17,76 \%, 50,66 \%, 67,10 \%$.

\section{GRÁFICO 5.1}

Apresenta a evolução acumulada de cada categoria tabelada com base na matriz curricular da SOCIESC

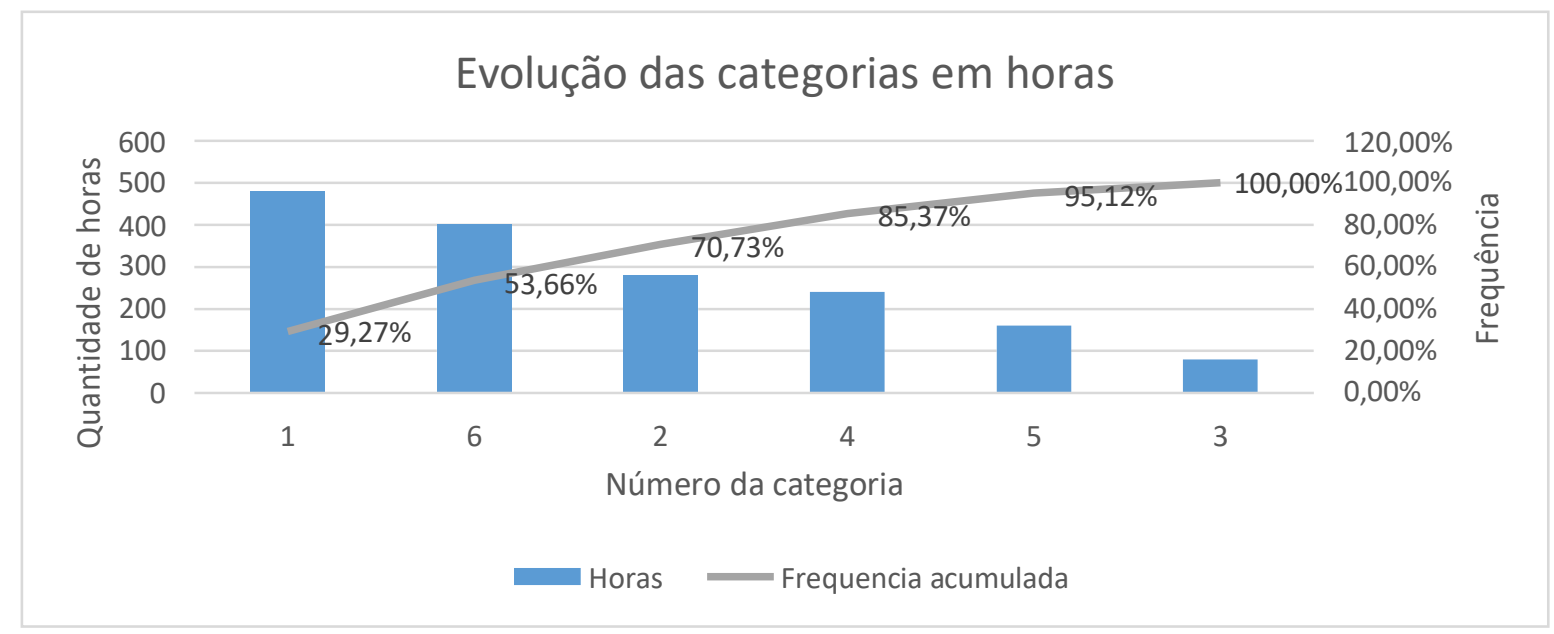

Fonte: O autor.

Na Gráfico 5.1 da SOCIESC a concentração de $70,73 \%$ do tempo do curso nas categorias 1, 6 e 2 (Ferramentas da Qualidade; Estatística e Métodos Quantitativos; e Gestão e Estratégias) o que indica o direcionamento do curso em seguir as principais técnicas de especialização do aluno nestas classes. Já os $29,27 \%$ restantes do curso indicam a tendência da universidade em apresentar os conhecimentos complementares através das categorias 4, 5 e 3 (Marketing, e Relações Humanas e Sociais; Processo e Produção; e Economia, Contabilidade e Custos;).

\section{CONSIDERAÇÕES FINAIS}


Ao decidir realizar uma análise comparativa entre diferentes universidades é necessário aceitar que na busca pela comparação de dados serão impostos critérios e que estes terão papel crucial nos resultados do trabalho. Segundo KUHN (1991) [...] devemos reconhecer que um paradigma pode ser muito limitado, tanto no âmbito como na precisão, quando de sua primeira aparição.

Não obstante podemos aceitar que vivemos em constante mudanças dentro das estruturas de sociedade e novos campos passíveis de pesquisa serão gerados. Segundo KUHN (1991) [...] fenômenos novos e insuspeitados são periodicamente descobertos pela pesquisa científica; cientistas têm constantemente inventado teorias radicalmente novas.

É por isso que se reconhece neste trabalho que a análise das matrizes curriculares e o seu comparativo não caracteriza a criação de um modelo ideal - até mesmo não é possível posicionar com exatidão em um tema tão amplo se o mercado de trabalho deseja ter tal modelo apenas pela análise das grades curriculares.

\section{TABELA 2}

Representa a ordem de representatividade das categorias dentro de cada entidade.

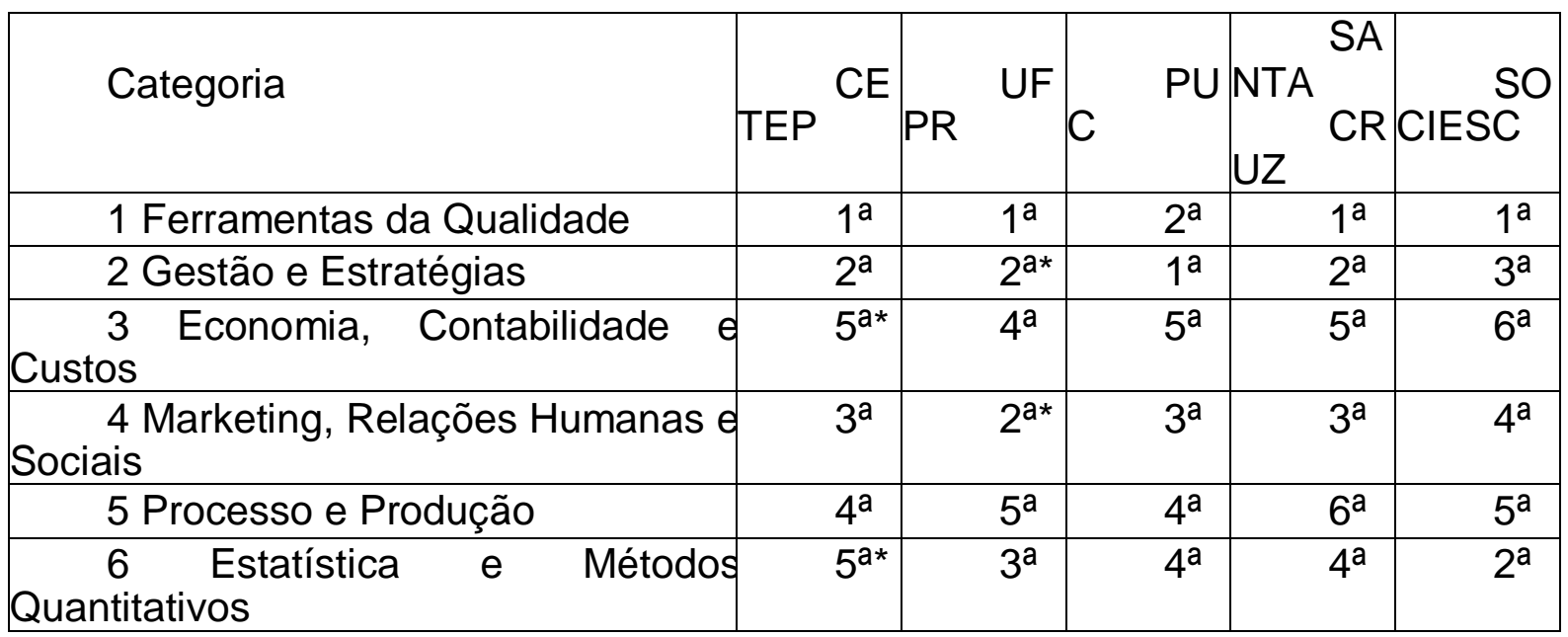

Fonte: $\mathrm{O}$ autor.

${ }^{*}$ Categoria com concentração horária igual.

A Tabela 2 exemplifica que cada curso tem a sua priorização e que muitas vezes possuem a mesma categoria na mesma etapa de priorização, apesar disso nenhuma matriz é igual a outra. Assumindo o conceito da qualidade e a sua variação podemos 
destacar que os cursos apresentam, sim, diversas similaridades como maior foco em categorias de Ferramentas da Qualidade; Gestão e Estratégias como no caso das entidades CETEP, PUC, UFPR e Santa Cruz. E diferenças como há na Sociesc um enfoque com grande representatividade para a categoria Estatística e Métodos Quantitativos. Além disso todos os cursos acabaram tendo um foco maior em 2 ou 3 categorias e outras 3 ou 4 apresentaram uma conotação complementar.

Segundo Moraes, Franco e Silva (2010) [...] o conceito de qualidade é leve, na medida em que se apresenta flexível e plurívoco; por outro lado é insustentável se os que são concernidos ao utilizarem tal conceito não o usam sob a mesma perspectiva [...]. O que corroborara a diferença existente entre as matrizes curriculares dos Cursos Superiores de Tecnologia em Gestão da Qualidade uma vez que cada avaliação do mercado feita pelas entidades pode ter observado uma tendência ou oportunidade diferente. Além disso, o simples fato da qualidade representar um termo diferente entre as pessoas influencia uma vez que cada um tem a sua perspectiva.

Destaco que este trabalho não teve o intuito de avaliar qual o melhor curso ou entidade e que poderiam ser criadas diversas metodologias para gerar comparativos. Contudo considero fundamental discussões e avalições sobre os cursos de Tecnologia e de Gestão da Qualidade, uma vez que representam algo novo e ainda pouco conhecido em relação a cursos tradicionais como Engenharia e Direito.

\section{REFERÊNCIAS}

FORD, HENRY. Missão, Visão e Política de Qualidade. Documento disponível em:<http://www.ford.com.br/sobre-a-ford/missao-visao-e-politica-de- qualidade>, acesso dia 01 de junho de 2015.

KUHN, Thomas. S. A estrutura das revoluções científicas. São Paulo: Perspectiva, 1991.

MACHADO, LUCÍLIA REGINA DE SOUZA. O Profissional Tecnólogo e sua Formação. Documento disponível em:< http://www.mestradoemgsedl.com.br/wpcontent/uploads/2010/06/O-profissional-tecn\%C3\%B3logo-e-suaforma\%C3\%A7\%C3\%A3o.pdf>, acessado dia 02 de junho de 2015.

MARISTA - GRUPO MARISTA. Missão, visão e valores. Documento disponível 
em:<http://www.grupomarista.org.br/institucional/?utm_source=barra_institucional\&u tm_medium=http://www.pucpr.br/\&utm_campaign=institucional>, acesso dia 15 de junho de 2016.

MEC - MINISTÉRIO DA EDUCAÇÃO E CULTURA. Decreto №5.777/06, e 9

de maio de 2006. Documento disponível em:< http://portal.mec.gov.br/setec/arquivos/pdf/dec_5773_06.pdf>, acesso dia 20 de junho de 2015.

MEC - MINISTÉRIO DA EDUCAÇÃO E CULTURA. Catálogo nacional para os cursos superiores de tecnologia. Documento disponível em:<http://portal.mec.gov.br/index.php?ltemid=86\&id=12352\&option=com_content>, acesso dia 01 de junho de 2015.

MORAES, Paulo Eduardo Sobreira, FRANCO, Maura Regina e SILVA, Guilherme R. S. Souza: Ensaio sobre a insustentável leveza do conceito de qualidade. Revista Qualidade Emergente, v.1, n.1, 2010.

PUCPR - PONTIFÍCIA UNIVERSIDADE CATÓLICA DO PARANÁ.

Institucional. Documento disponível em:<

http://www.pucpr.br/institucional/index.php>, acesso dia 14 de junho de 2016.

PUCPR - PONTIFÍCIA UNIVERSIDADE CATÓLICA DO PARANÁ. Gestão

da Qualidade. Documento disponível em:<

http://www.pucpr.br/tecnologos/gestaoqualidade/>, acessado dia 14 de junho de 2016.

UTFPR - UNIVERSIDADE TECNOLOGICA FEDERAL DO PARANÁ.

Orientação para das diretrizes curriculares dos cursos de graduação. Documento disponível

em:<http://www.utfpr.edu.br/estrutura-universitaria/proreitorias/prograd/legislacao/arquivos/tecnologia/par_cne_ces776.pdf>, acesso dia 01 de junho de 2015.

UFPR - UNIVERSIDADE FEDERAL DO PARANÁ. Histórico. Documento disponível em:< http://www.ufpr.br/portalufpr/historico-2/>, acessado dia 13 de junho de 2015.

SOCIESC - SOCIEDADE EDUCACIONAL DE SANTA CATARINA. Histórico

Sociesc. Documento disponível em:<

http://unisociesc.org.br/pt/institucional/conteudo.php?\&id=4468\&lng=2\&mnu=5827\&t op=0> acessado dia 15/11/2016

TGQ - TECNOLOGIA EM GESTÃO DA QUALIDADE. Reformulação 
curricular de projeto pedagógico do curso superior de Tecnologia em Gestão da Qualidade. Documento disponível em:<

http://www.gestaodaqualidade.ufpr.br/wp-

content/uploads/2016/03/PP_Projeto_Pedag\%C3\%B3gico_TGQ.pdf>, acessado dia $15 / 11 / 2016$ 